University of Wollongong

Research Online

Faculty of Engineering and Information

Faculty of Engineering and Information

Sciences - Papers: Part A

Sciences

2017

Improvement of microstructure and properties in twin-roll casting 7075

sheet by lower casting speed and compound field

G Chen

Northeastern University

Jintao Li

University of Wollongong, j1221@uowmail.edu.au

Z K. Yin

Northwestern Polytechnical University

G M. Xu

Northeastern University, xu_gm@epm.neu.edu.cn

Follow this and additional works at: https://ro.uow.edu.au/eispapers

Part of the Engineering Commons, and the Science and Technology Studies Commons

Research Online is the open access institutional repository for the University of Wollongong. For further information contact the UOW Library: research-pubs@uow.edu.au 


\title{
Improvement of microstructure and properties in twin-roll casting 7075 sheet by lower casting speed and compound field
}

\author{
Abstract \\ Well-developed dendrites and severe macro and micro segregations in 7075 sheet produced by horizontal \\ twin-roll casting (TRC) deteriorates the hot-workability and properties of the sheet, which makes an \\ obstacle for the successful use of this technology. In this paper, lower casting speed and a pulsed \\ electric-magnetostatic compound field are used to refine microstructure and abate segregation in TRC \\ 7075 sheet. The dendrite arm space decreases from $20 i \mathrm{~m}$ to $8 i 13 i \mathrm{~m}$ and the micro-segregation degree \\ of $\mathrm{Mg}, \mathrm{Zn}$ and $\mathrm{Cu}$ decreases when casting speed decreases from $1.5 \mathrm{~m} / \mathrm{min}$ to $0.75 \mathrm{~m} / \mathrm{min}$. The center \\ macro-segregation belt disappears in the $0.75 \mathrm{~m} / \mathrm{min}$ sheet. The as-cast structure and the dendritic \\ segregation in the $0.75 \mathrm{~m} / \mathrm{min}$ sheet are further refined and abated respectively by the compound field. \\ The secondary dendrite arm size decreases to $5 i 8 i \mathrm{~m}$ in the field sheet. The $0.75 \mathrm{~m} / \mathrm{min}$ sheet casted \\ with the field shows better mechanical properties after homogenization and hot rolling. The optimization \\ mechanism of lower casting speed and the field was discussed with the aid of classical solidification \\ theory and electromagnetism.

\section{Disciplines} \\ Engineering | Science and Technology Studies

\section{Publication Details} \\ Chen, G., Li, J. T., Yin, Z. K. \& Xu, G. M. (2017). Improvement of microstructure and properties in twin-roll \\ casting 7075 sheet by lower casting speed and compound field. Materials Characterization, 127 325-332.
}




\title{
Improvement of Microstructure and Properties in Twin-roll Casting 7075 Sheet by Lower Casting Speed and Compound Field
}

\author{
G. Chen ${ }^{\text {a }}$, J.T. Li ${ }^{\text {a, b }}$, Z.K. Yin ${ }^{c}$, G.M. Xu ${ }^{\text {a, * }}$
}

${ }^{a}$ Key Laboratory of Electromagnetic Processing of Materials (Ministry of Education), Northeastern University, Shenyang 110819, PR China

${ }^{\mathrm{b}}$ School of Mechanical, Materials and Mechatronic Engineering, University of Wollongong, Wollongong, NSW 2500, Australia

${ }^{\mathrm{c}}$ Department of Materials Science and Engineering, Northwestern Polytechnical University, Xi'an 710072, PR

China

Abstract: Well-developed dendrites and severe macro and micro segregations in 7075 sheet produced by horizontal twin-roll casting (TRC) deteriorate the hot-workability and properties of the sheet, which makes an obstacle for the successful use of this technology. In this paper, lower casting speed and a pulsed electric-magnetostatic compound field are used to refine microstructure and abate segregation in TRC 7075 sheet. The dendrite arm space decreases from $20 \mu \mathrm{m}$ to $8 \sim 13 \mu \mathrm{m}$ and the micro-segregation degree of $\mathrm{Mg}, \mathrm{Zn}$ and $\mathrm{Cu}$ decreases when casting speed decreases from $1.5 \mathrm{~m} / \mathrm{min}$ to $0.75 \mathrm{~m} / \mathrm{min}$. The center macro-segregation belt disappears in the $0.75 \mathrm{~m} / \mathrm{min}$ sheet. The as-cast structure and the dendritic segregation in the $0.75 \mathrm{~m} / \mathrm{min}$ sheet are further refined and abated respectively by the compound field. The secondary dendrite arm size decreases to $5 \sim 8 \mu \mathrm{m}$ in the field sheet. The $0.75 \mathrm{~m} / \mathrm{min}$ sheet casted with the field shows better mechanical properties after homogenization and hot rolling. The optimization mechanism of lower casting speed and the field was discussed with the aid of classical solidification theory and electromagnetism.

Keywords: 7075 sheet; twin-roll casting; casting speed; compound field; segregation 


\section{Introduction}

As a kind of ultra-high strength aluminum alloy, 7075 alloy is widely used in many fields like construction of plane structures, automotive components, sports and electronic industries due to its superior comprehensive properties, such as low density, high specific strength, toughness and resistance to fatigue[1-4]. The traditional method of producing 7075 sheet is direct chill (DC) casting followed by hot rolling [5], which has the disadvantage of complex process and high cost. Unlike this method, twin-roll casting (TRC) can produce sheet directly from melt and thus has the advantage of short procedure, energy saving and low cost [6]. However, severe segregation and well-developed columnar dendrites always occur in TRC 7075 sheet as a result of directional solidification as well as high content elements and wide solidification temperature range in the alloy [7]. These segregated phases often form a network-like structure and provide easy path for crack growth during hot plastic deformation at low temperatures [7]. They also cause partial melting due to eutectic reaction at high temperatures, which narrows the temperature and strain rate ranges for successful hot working [7].

During TRC of aluminum, process parameters such as pouring temperature and casting speed decide whether the sheet can be produced smoothly as well as the microstructure of the sheet. Sun et al. [8] pointed out that high casting speed tended to form macro-segregation in the TRC sheet center. Thus the metallurgical defects in the TRC 7075 sheet maybe abated by adjusting the casting speed. Besides, as stated by Asai [9], applying electric current and magnetic field would induce an electromagnetic oscillation in the melt. As a result, the growing crystals can be shattered and refined and the segregation abated. What's more, compared with traditional refining methods, the application of magnetic field is completely free from contamination and the imposition of electric current is extremely clean, except for contamination from electrodes [9]. 
Several researches on 7075 sheet produced by TRC have been carried out recently. Wang et al. [10] studied the effects of microstructure of TRC 7075 sheet on its hot tensile behavior and found that large elongation over $200 \%$ was obtained at $450{ }^{\circ} \mathrm{C}$ under high strain rate of $1 \times 10^{-1} \mathrm{~s}^{-1}$. This large elongation was caused by the uniformly distributed small particles in TRC sheet casted at high solidification rate, which induced homogeneous recrystallized microstructure during the hot deformation. Su et al. [5, 11-12] studied horizontal TRC of 7075 sheet. Electromagnetic fields were used during the process to abate both the micro and macro segregation and to refine the microstructure. However, in these works, the effects of casting parameters were not investigated and the function mechanism of the electromagnetic fields was not studied in detail.

In this paper, a 7075 sheet was produced by horizontal TRC. Different casting speeds were used to study their effects on the microstructure of the sheet. A compound field (pulsed electric field combined with magnetostatic field) was applied during casting to study its effects on the as-cast microstructure and elements segregation in the sheet. The paper aims at finding an effective way to abate the metallurgical defects in the 7075 TRC sheet and thus puts the technology into practice.

\section{Experiment and material}

The TRC was carried out on a reversible horizontal twin-roll caster with two rollers $500 \mathrm{~mm}$ in diameter and $500 \mathrm{~mm}$ wide. The maximum rolling force was $1000 \mathrm{kN}$. Two roll gaps of $5 \mathrm{~mm}$ and $3.8 \mathrm{~mm}$ were used. The roller surface was smeared with graphite powder to avoid sticking. A refractory nozzle was used to direct melt into the roll gap. Two home-made coils were used to generate magnetostatic field in the roll-casting zone. One of the coils was put under the nozzle and the other at the exit side near the roll gap. The maximum vertical magnetic flux density in the cast-rolling zone was about $45 \mathrm{mT}$. The pulsed electric field (PEF) was generated with a pulse stabilized power supply. The peak value, frequency and duty ratio were set to $600 \mathrm{~A}, 20 \mathrm{~Hz}$ and 
$15 \%$, respectively. One end of the PEF wire was inserted into melt and the other end was pressed on the sheet surface to form loop. The schematic diagram of TRC is shown in Fig. 1(a) and the corresponding sizes of roll-casting zone are in Fig. 1(b). 7075 alloy was smelted in a $20 \mathrm{~kW}$ resistance furnace by firstly melting commercially pure (99.9 \%) aluminum ingot. When the melt temperature reached $750{ }^{\circ} \mathrm{C}$, commercially pure magnesium and zinc ingot and master alloys of $\mathrm{Cu}$ and $\mathrm{Cr}$ were put into the melt. The melt was hold at this temperature for 2 hours. Then the melt was cooled to $680{ }^{\circ} \mathrm{C}$ and poured into the nozzle through a sluice. The chemical composition of the 7075 alloy in wt $\%$ was $\mathrm{Al}-5.59 \mathrm{Zn}-2.92 \mathrm{Mg}-1.88 \mathrm{Cu}-0.239 \mathrm{Cr}-0.46 \mathrm{Fe}-0.4 \mathrm{Si}$. Two casting speeds of 0.75 $\mathrm{m} / \mathrm{min}$ and $1.5 \mathrm{~m} / \mathrm{min}$ were used when the roll gap was $5 \mathrm{~mm}$ and $3.8 \mathrm{~mm}$, respectively. In the first casting, the magnetostatic field and PEF were applied on half of the sheet and the other half casted without external field. The width and thickness of the as-cast sheet were about $210 \mathrm{~mm}$ and $7 \mathrm{~mm}$ (or $5 \mathrm{~mm}$ ), respectively.

(a)

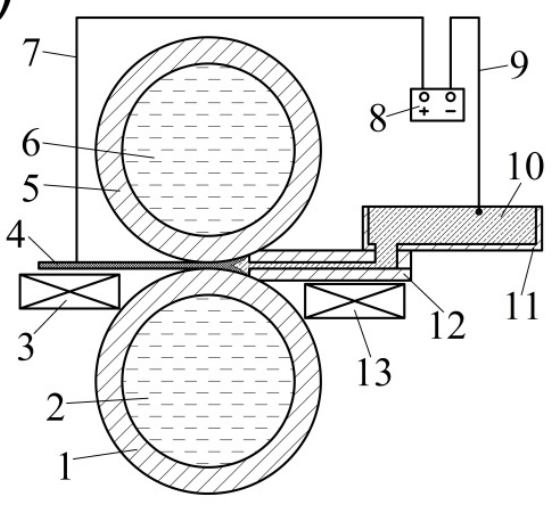

(b)

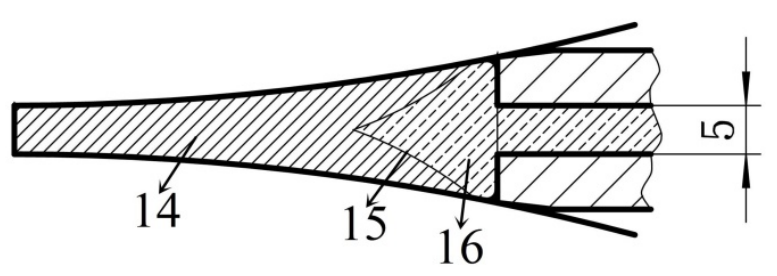

Fig. 1 (a) Schematic diagram of electromagnetic TRC and (b) the roll-casting zone: 1-lower roller; 2 and 6-cooling water; 3 and 13-coil; 4-7075 sheet; 5-upper roller; 7 and 9-PEF wire; 8- pulsed power supply; 10 and 16-7075 melt; 11-sluice; 12-nozzle; 14-solidified alloy; 15- solidification interface

Small pieces of $50 \mathrm{~mm} \times 150 \mathrm{~mm}$ were cut from the as-cast sheets to be further treated. Firstly, the pieces were homogenized in a resistance furnace at $460 \pm 5^{\circ} \mathrm{C}$ for 12 hours and furnace cooled 
to room temperature. Then the sheets were hot rolled at a temperature range of $410 \sim 430{ }^{\circ} \mathrm{C}$ to a final thickness of $1.5 \mathrm{~mm}$ followed by a stress relief annealing at $390{ }^{\circ} \mathrm{C}$ for $30 \mathrm{~min}$. Metallographic specimens were cut from the as-cast and homogenized sheets respectively to study their microstructures. The samples were studied under a Leica DMI5000M optical microscopy (OM) after being ground, polished and then etched with 3 vol \% HF aqueous solution for 15 20 s. To study the precipitated phases and elements segregation in the differently treated sheets, SSX-550 scanning electron microscopy (SEM) equipped with energy dispersive X-ray spectrometry (EDS) was used. The dendritic segregation was investigated with the micro-segregation degree $S_{e}$ using the following equation:

$$
S_{e}=\frac{C_{\max }-C_{\min }}{C_{0}}
$$

where $C_{\max }, C_{\min }, C_{0}$ are the maximum, minimum and average content of an element in the segregation zone repectively. The mechnical properities of the hot rolled sheets were investigated by tensile testing on a SHIMADZU AG-X universal testing machine at a speed of $2 \mathrm{~mm} / \mathrm{min}$ (corresponding to a strain rate of $0.001 \mathrm{~s}^{-1}$ ). The test samples were cut from the hot-rolled and annealed sheets along the rolling direction on a wire cutting machine. The gage length and width of the tensile sample were $34 \mathrm{~mm}$ and $10 \mathrm{~mm}$, respectively. To make the test results as reliable as possible, three samples were prepared for each condition and the average values of the eigenvalues of the tensile curves were used in the analysis. The fracture morphology was studied on the SSX-550 SEM.

\section{Results}

\subsection{Microstructures of the as-cast sheet}

Fig. 2 shows the transverse microstructure of as-cast sheet under different casting conditions. Fig. 
2(a) and Fig. 2(b) show the near surface and center part in the $1.5 \mathrm{~m} / \mathrm{min}$ sheet respectively. Well-developed dendrites can be seen in the near surface part and the size of the dendrite arms is not homogeneous and within a range of 15 25 $\mu \mathrm{m}$. Besides, some coarse worm shaped segregations $30 \sim 50 \mu \mathrm{m}$ wide and 100 200 $\mu \mathrm{m}$ long can be observed in the upper right corner. In the center part, a $20 \sim 80 \mu \mathrm{m}$ wide macro-segregation belt is observed. Above the belt, some very fine dendrites appear and the crystal structure is heterogeneous. Fig. 2(c) and Fig. 2(e) show the near surface and center part of the $0.75 \mathrm{~m} / \mathrm{min}$ sheet casted without the compound field. The near surface part also consists of well-developed dendrites with an average arm size of $8 \sim 13 \mu \mathrm{m}$ and many worm shaped segregation zones $5 \sim 10 \mu \mathrm{m}$ wide and $50 \sim 70 \mu \mathrm{m}$ long. The sizes of the dendrite arms and segregation zones are much smaller than in the $1.5 \mathrm{~m} / \mathrm{min}$ sheet. The macro-segregation belt disappears in the center part and the microstructure is much the same as near surface part. In the $0.75 \mathrm{~m} / \mathrm{min}$ sheet casted with the compound field shown in Fig. 2(d) and Fig. 2(f), the dendrites are further refined compared with the non-field condition and with a smaller and more uniform size of 5 8 $\mu \mathrm{m}$. What's more, the number of the worm shaped segregation apparently decreases and the size of the rest diminishes to some extent. The average dendrite arm size in the as-cast 7075 sheet under different casting conditions is shown in Fig. 3 to make the effect of casting speed and the field shown more apparently. The arm size decreases markedly under lower casting speed and the compound field. 

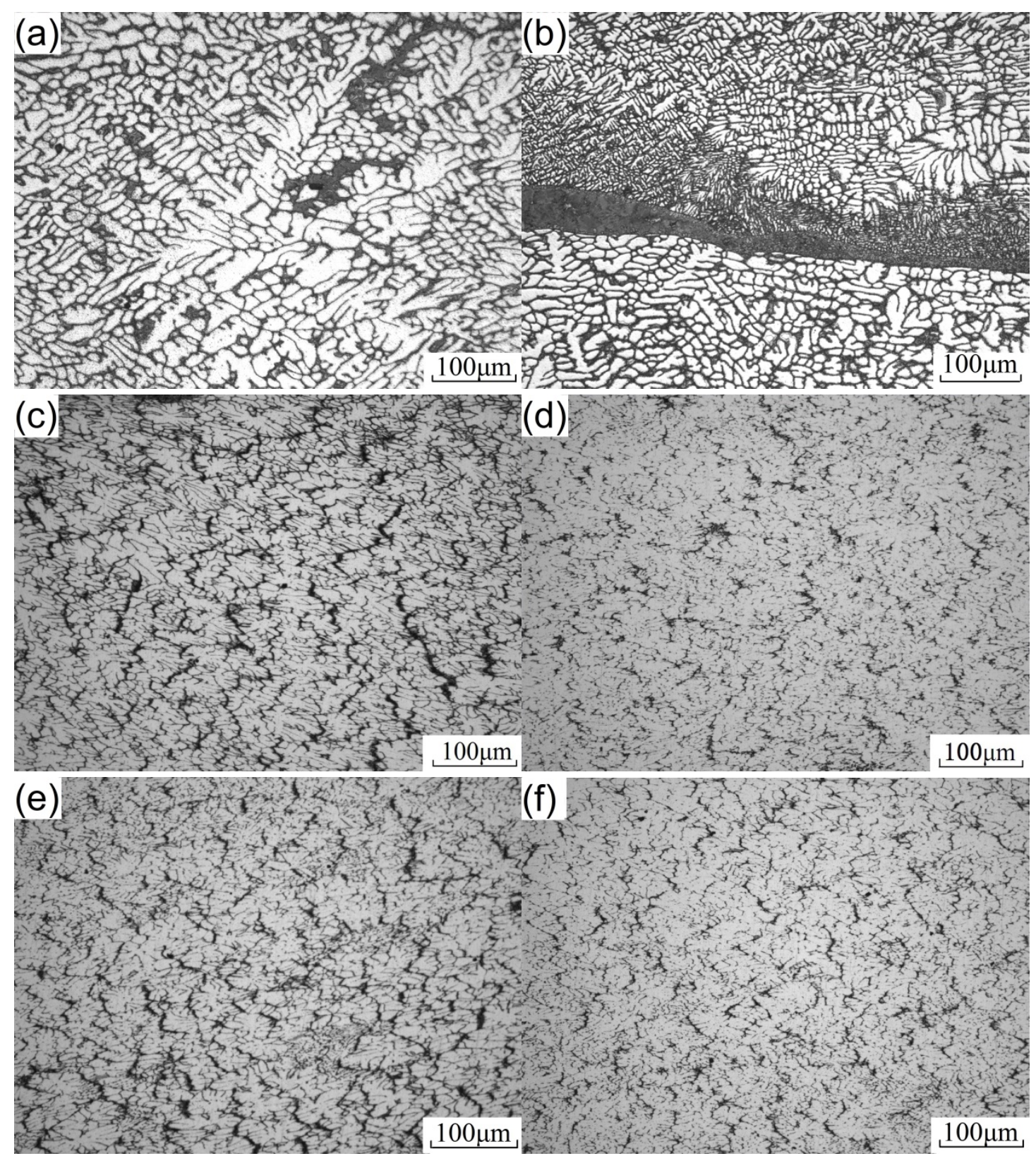

Fig. 2 Microstructure of as-cast TRC 7075 sheet: (a) $1.5 \mathrm{~m} / \mathrm{min}$, near surface; (b) $1.5 \mathrm{~m} / \mathrm{min}$, center; (c) 0.75 $\mathrm{m} / \mathrm{min}$, near surface, non-field; (d) $0.75 \mathrm{~m} / \mathrm{min}$, near surface, field; (e) $0.75 \mathrm{~m} / \mathrm{min}$, center, non-field; (f) 0.75 $\mathrm{m} / \mathrm{min}$, center, field

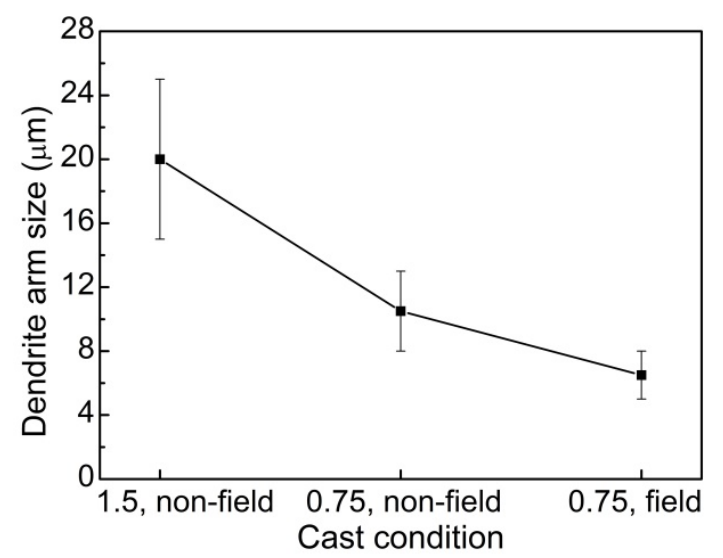

Fig. 3 Average dendrite arm size in as-cast 7075 sheet under different casting conditions 
Fig. 4 shows the SEM microstructure of the as-cast sheets. Fig. 4(a) and Fig. 4(b) show the near surface and center part in the $1.5 \mathrm{~m} / \mathrm{min}$ sheet, respectively. It can be seen the worm shaped segregation zones in Fig. 2(a) (marked as “A” in Fig. 4(a)) and the macro-segregation belt in Fig. 2(b) (marked as "B” in Fig. 4(b)) are both the typical grain boundary (GB)-eutectic phases [13]. The compositions of the two phases are shown in Table 1 and both have high amounts of Mg and Zn and a little $\mathrm{Cu}$ in them. Fig. 4(c) shows the $0.75 \mathrm{~m} / \mathrm{min}$ sheet without field. The GB-eutectic phase is also observed in the sheet as marked out with the circles and "C". However, the size of the phase is much smaller than in the $1.5 \mathrm{~m} / \mathrm{min}$ sheet. The composition result in Table 1 shows the phase also has $\mathrm{Zn}, \mathrm{Mg}$ and $\mathrm{Cu}$ in it. Compared with the $1.5 \mathrm{~m} / \mathrm{min}$ cases, $\mathrm{Zn}$ content is higher whereas $\mathrm{Mg}$ and $\mathrm{Cu}$ content is lower. Besides this phase, two other GB phases are found in the sheet. The white phase marked as " $\mathrm{D}$ " has nearly same composition as the GB-eutectic phase whereas the black phase marked as "E" is mainly $\mathrm{Al}$ matrix with some Fe in it. Fig. 4(d) shows the $0.75 \mathrm{~m} / \mathrm{min}$ sheet with field. Compared with the non-field sheet, the size of the GB phases is smaller and scarcer. The composition of these phases is nearly same as the white phase marked as " $D$ " in Fig. 4(c).
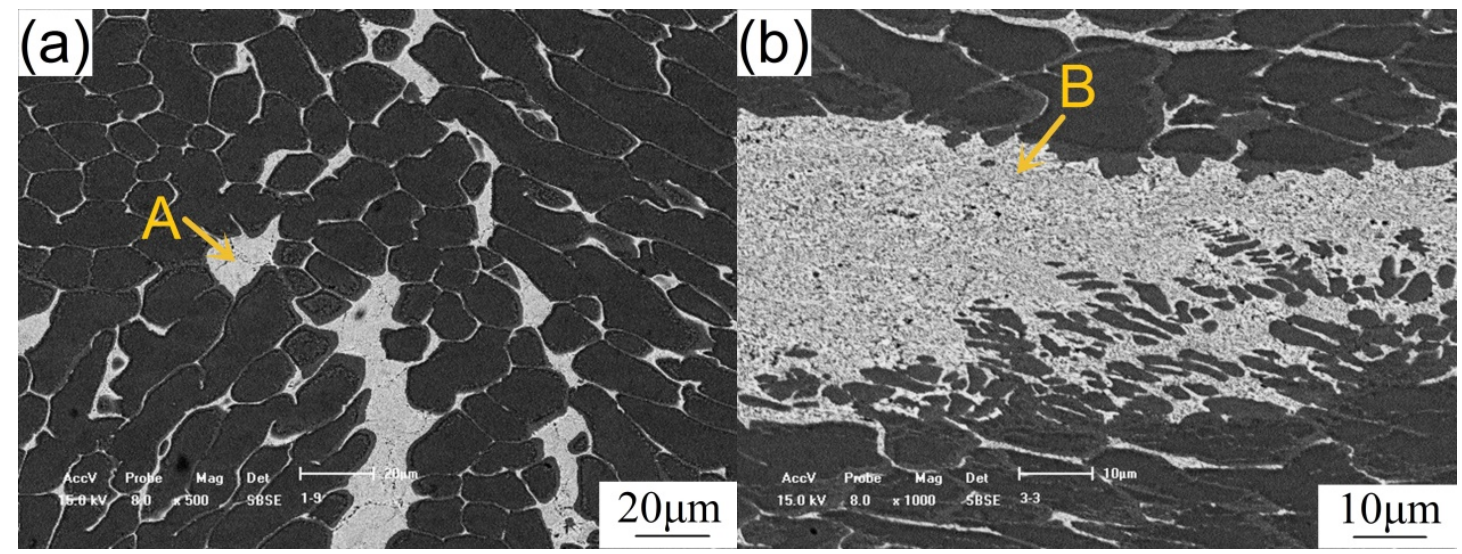


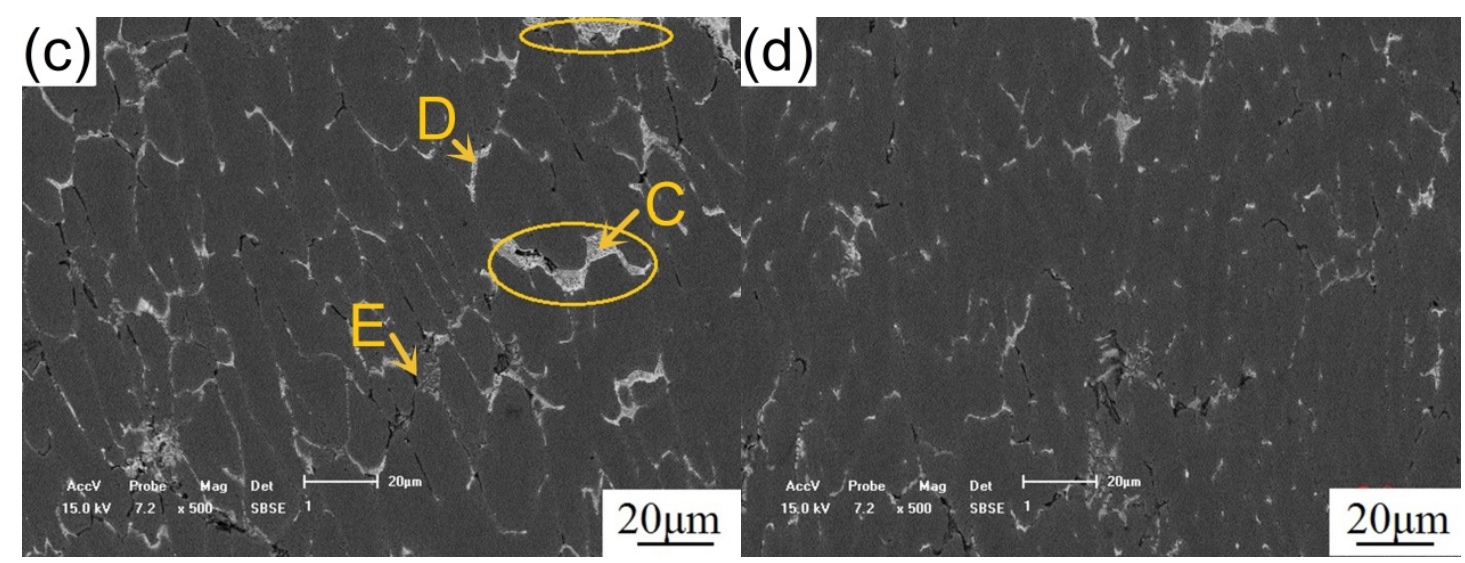

Fig. 4 SEM microstructure of as-cast TRC 7075 sheet under different conditions: (a) $1.5 \mathrm{~m} / \mathrm{min}$, near surface; (b) $1.5 \mathrm{~m} / \mathrm{min}$, center; (c) $0.75 \mathrm{~m} / \mathrm{min}$, non-field; (d) $0.75 \mathrm{~m} / \mathrm{min}$, field.

Table 1 Compositions of phases marked out in Fig. 4, at \%.

\begin{tabular}{cccccc}
\hline Position & $\mathrm{Mg}$ & $\mathrm{Al}$ & $\mathrm{Zn}$ & $\mathrm{Cu}$ & $\mathrm{Fe}$ \\
\hline $\mathrm{A}$ & 23.05 & 59.42 & 11.75 & 5.78 & - \\
B & 21.94 & 52.23 & 16.14 & 9.69 & - \\
C & 8.57 & 63.91 & 23.15 & 4.37 & - \\
D & 12.34 & 63.09 & 17.44 & 7.13 & - \\
E & 1.82 & 86.85 & 2.93 & 3.42 & 4.98 \\
\hline
\end{tabular}

To further study the dendritic segregation in the as-cast sheet under different casting conditions, EDS line scanning was carried out and the results are in Fig. 5. The green lines in the left images show the scanning positions and the corresponding results on the right. The scanning line passed through at least one dendrite arm. Fig. 5(a1) and Fig. 5(a2) show the result of the near surface part in the $1.5 \mathrm{~m} / \mathrm{min}$ sheet while the center part in Fig. 5(b1) and Fig. 5(b2). It can be observed the elements content is higher in the dendrite arm boundaries than inside the arms. The scanning position and result of the $0.75 \mathrm{~m} / \mathrm{min}$ sheet without field are shown in Fig. 5(c1) and Fig. 5(c2) and the sheet with field shown in Fig. 5(d1) and Fig. 5(d2). The content of the elements is also higher at the arm boundaries than inside the arms. However, the content discrepancy is somewhat smaller than in the $1.5 \mathrm{~m} / \mathrm{min}$ condition. 

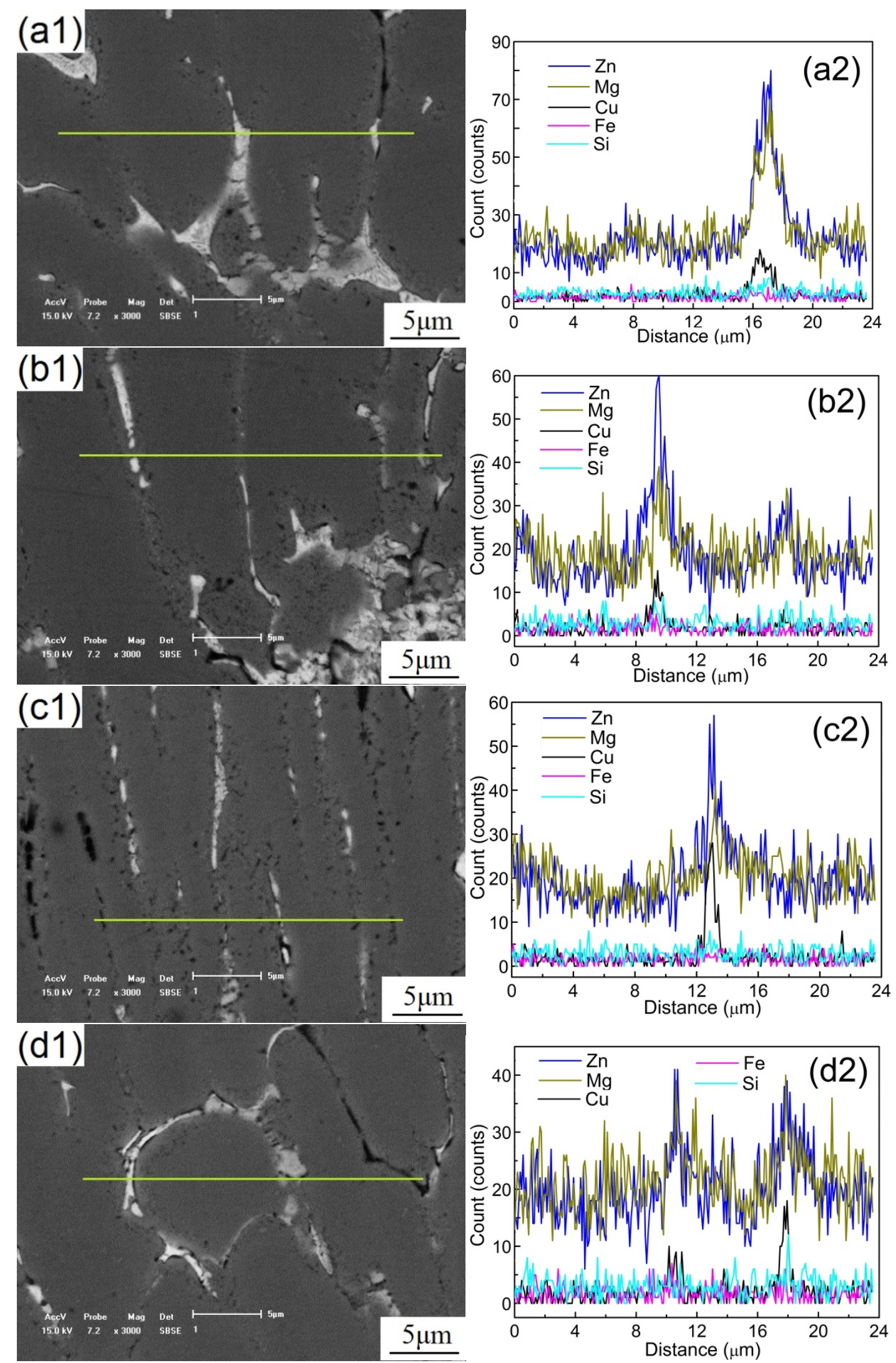

Fig. 5 Element distribution across dendrite arms in as-cast sheet, scanning position on left and the results on right: (a1) \& (a2) near surface, $1.5 \mathrm{~m} / \mathrm{min}$; (b1) \& (b2) center, $1.5 \mathrm{~m} / \mathrm{min}$; (c1) \& (c2) $0.75 \mathrm{~m} / \mathrm{min}$, non-field; (d1) \& (d2) $0.75 \mathrm{~m} / \mathrm{min}$, field

Micro-segregation degree $S_{e}$ of elements $\mathrm{Zn}, \mathrm{Mg}$ and $\mathrm{Cu}$ was calculated based on the results in 
Fig. 5 to quantitatively analyse the dendritic segregation and the results are in Fig. 6 . The $S_{e}$ in both the near surface and center part of the $1.5 \mathrm{~m} / \mathrm{min}$ sheet is higher than that in the coresponding parts of $0.75 \mathrm{~m} / \mathrm{min}$ sheet. After applying the field, the $S_{e}$ in both the near surface and center part of the $0.75 \mathrm{~m} / \mathrm{min}$ sheet further decreases to some extent. The $S_{e}$ result is consistant with the microstructrue differences in Fig. 4.
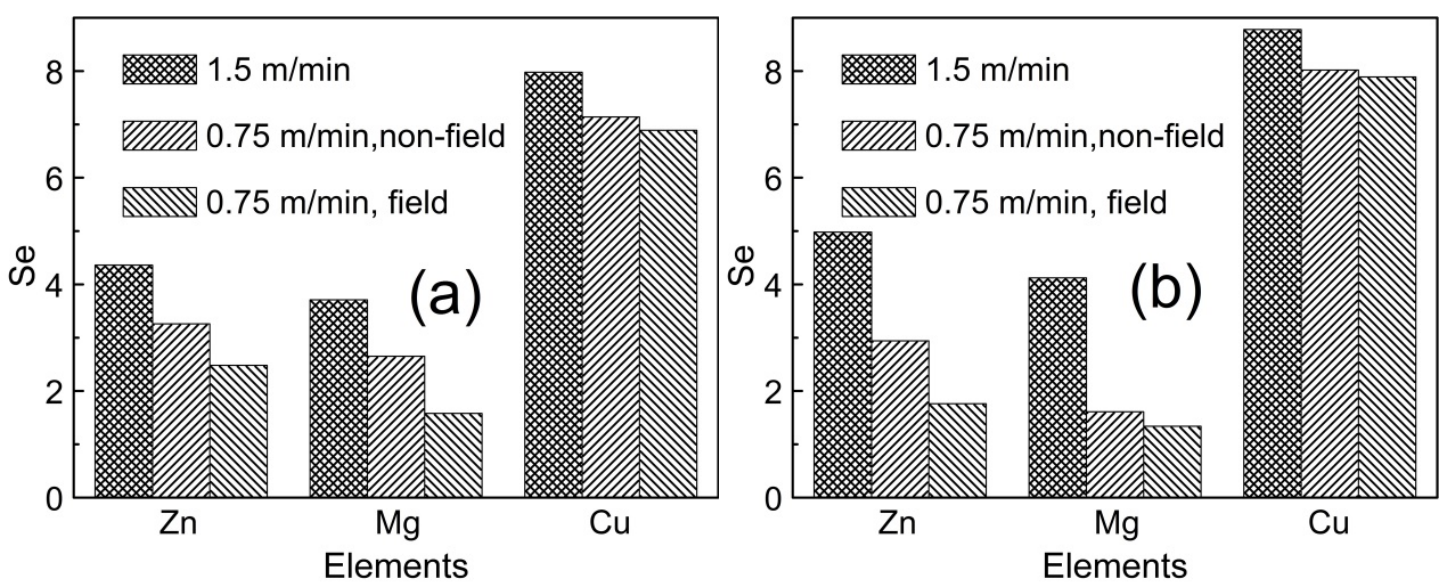

Fig. 6 Micro-segregation degree $S_{e}$ of near surface and center parts in as-cast TRC 7075 sheet under different conditions: (a) near surface; (b) center

\subsection{Properties of homogenized and hot-rolled sheets}

The SEM microstructure of the sheets after homogenization is shown in Fig. 7. Fig. 7(a) and Fig. 7(b) show the near surface and center part respectively in the $1.5 \mathrm{~m} / \mathrm{min}$ sheet and Fig. 7(c) and Fig. 7(d) the $0.75 \mathrm{~m} / \mathrm{min}$ sheet without and with the field respectively. Many dot-like and needle-like precipitated particles can be seen in the homogenized sheets. The dot-like particles are with an average diameter of $\sim 0.5 \mu \mathrm{m}$ and the needle-like phases are $1 \mu \mathrm{m}$ wide and $\sim 3 \mu \mathrm{m}$ long medially. According to Liu [14], these needle-like precipitates were nucleated on dispersoids during slow cooling. That is, during the furnace cooling, these needle-like phases would precipitate from the supersaturated matrix and the dispersoids acted as the nucleuses. The needle-like particles in the 1.5 $\mathrm{m} / \mathrm{min}$ sheet are scarcer than in the $0.75 \mathrm{~m} / \mathrm{min}$ sheet. Some large worm-shaped phases can be seen 
in the $1.5 \mathrm{~m} / \mathrm{min}$ sheet in Fig. 7(a), which disappeared in the $0.75 \mathrm{~m} / \mathrm{min}$ sheet in Fig. 7(c) and Fig. 7(d). The EDS results show these coarse phases have Fe and Si in them. As pointed out by CONG [15] and Hechta [16], these particles rich in Fe and Si can deteriorate the hot workability and limit the range of applicable process parameters during subsequent hot deformation and deteriorate the toughness and fatigue properties of the final product.

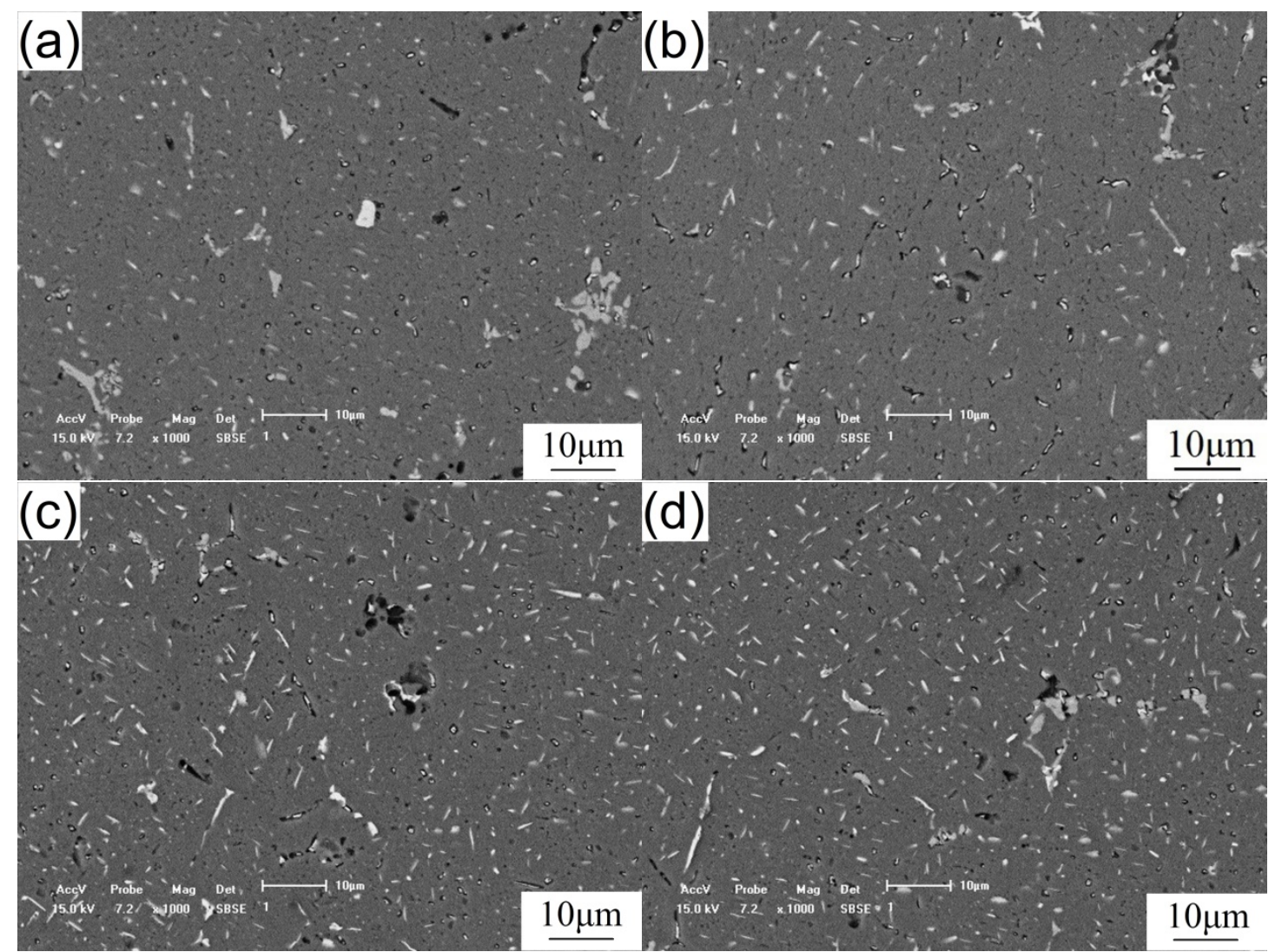

Fig. 7 SEM microstructure of TRC 7075 sheet after homogenization: (a) near surface, $1.5 \mathrm{~m} / \mathrm{min}$; (b) center, 1.5 $\mathrm{m} / \mathrm{min}$; (c) $0.75 \mathrm{~m} / \mathrm{min}$, non-field; (d) $0.75 \mathrm{~m} / \mathrm{min}$, field.

Fig. 8 shows the strain-stress curves of the hot rolled sheets. The eigenvalues are shown in the table. Both the tensile strength $\left(\mathrm{R}_{\mathrm{m}}\right)$ and elongation $(\mathrm{A})$ of the $1.5 \mathrm{~m} / \mathrm{min}$ sheet are lower than that of the $0.75 \mathrm{~m} / \mathrm{min}$ sheets. The $0.75 \mathrm{~m} / \mathrm{min}$ sheet casted with field has higher tensile strength than the non-field sheet whereas a slightly lower elongation. This means the mechanical property of the sheet was improved by the lower casting speed and the compound field. 


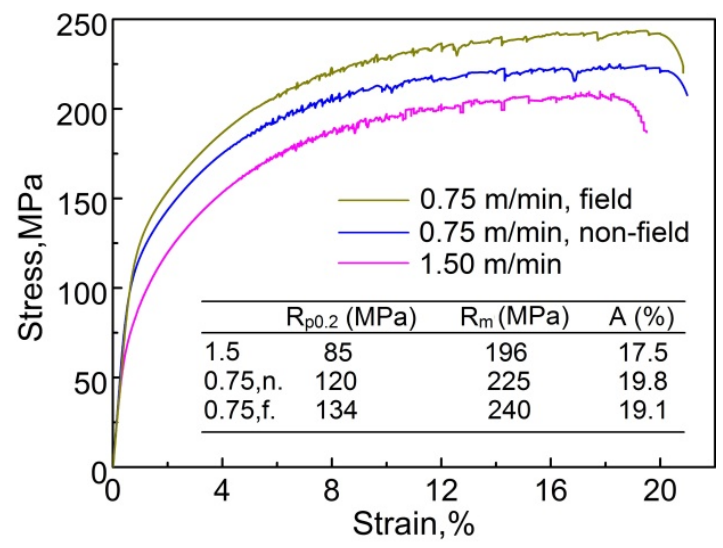

Fig. 8 Stress-strain curves of TRC 7075 sheet after hot rolling and stress relief annealing

The fracture morphology of the hot rolled sheet is shown in Fig. 9. Fig. 9(a) shows the $1.5 \mathrm{~m} / \mathrm{min}$ case and Fig. 9(b) and Fig. 9(c) show the $0.75 \mathrm{~m} / \mathrm{min}$ case without and with the field respectively. Dimples can be observed in all cases and these in the two $0.75 \mathrm{~m} / \mathrm{min}$ cases are bigger and deeper. Moreover, some quasi cleavage planes can be seen in the $1.5 \mathrm{~m} / \mathrm{min}$ case. These differences are the result of the better ductility of the $0.75 \mathrm{~m} / \mathrm{min}$ sheets as shown in Fig. 8. Moreover, the dimples in the $0.75 \mathrm{~m} / \mathrm{min}$ +field case are somewhat shallower than in the non-field case. This is because the field sheet has higher strength and lower ductility.

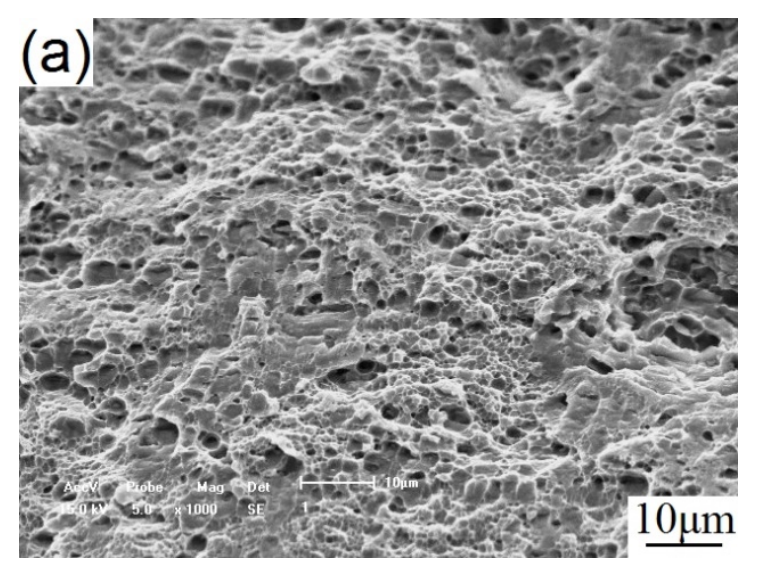




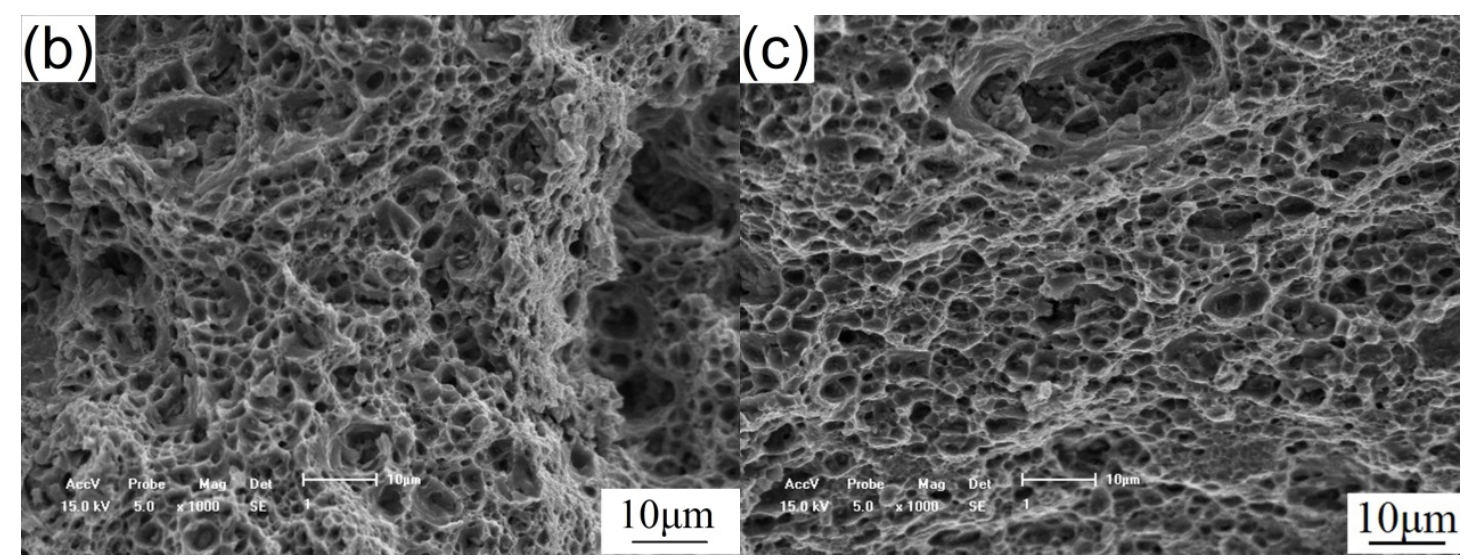

Fig. 9 Fracture morphology of 7075 sheet after hot rolling and stress relief annealing: (a) $1.5 \mathrm{~m} / \mathrm{min}$; (b) 0.75 $\mathrm{m} / \mathrm{min}$, non-field; (c) $0.75 \mathrm{~m} / \mathrm{min}$, field.

\section{Discussion}

One apparent feature of TRC process that distinguishes it from the traditional direct chill (DC) casting is the large thermal gradient along the thickness direction, which results in rapid directional solidification [8, 17]. As a result, together with the rolling effect, inclined columnar dendrites, equiaxed dendrites and center segregation are common crystalline characteristics in as-cast TRC sheets $[6,18]$. The sampling plane in Fig. 2 was vertical to rolling direction and beveling the inclined columnar dendrites. Thus equiaxed dendrites are observed. As the content of solute elements in 7075 alloy is relatively high and the alloy has a solute redistribution partition coefficient less than unity, a solute-rich boundary layer will be readily generated in front of the crystallizing interface. Hence, a compositional segregation region is produced ahead of the crystallizing front [19]. Moreover, due to the high cooling intensity in TRC, the adding elements had little time to diffuse in the matrix to ensure a uniform distribution and this inevitably led to concentration gradients across the primary $\alpha(\mathrm{Al})$ grains and finally the dendritic segregation [20]. During solidification, the columnar dendrites grow from the upper and lower roller surface to the sheet center. The elements in the dendrite boundaries are pushed gradually by the rolling effect to the center and finally form the macro-segregation belt. 
During TRC, the cooling intensity in the cast-rolling zone is mainly determined by casting speed and set-back distance. In present study, the set-back distance is nearly same for the two roll gaps of $5 \mathrm{~mm}$ and $3.8 \mathrm{~mm}$. The contacting time of the melt to roll surface in $1.5 \mathrm{~m} / \mathrm{min}$ case is nearly half of that in the $0.75 \mathrm{~m} / \mathrm{min}$ case. Thus the cooling intensity in the latter case is twice higher than in the former. According to Hadadzadeh [21], the relationship between cooling rate and dendrite arm spacing can be described by the following equation:

$$
2 \mathrm{~S}=35.5 R^{-0.31}
$$

where $R$ is the averaged cooling rate (in ${ }^{\circ} \mathrm{C} / \mathrm{s}$ ) and $S$ is the half-length of the secondary dendrite arm spacing (in $\mu \mathrm{m}$ ). With the increment of the cooling rate, the dendrite arm spacing decreases. The higher the cooling intensity, the higher the cooling rate is. This can explain the relatively smaller dendrite arm spacing in the $0.75 \mathrm{~m} / \mathrm{min}$ sheet than in the $1.5 \mathrm{~m} / \mathrm{min}$ sheet. Moreover, the rolling reduction increases when the cooling intensity enhances and this can also refine the dendritic arms.

It has to be pointed out that Equation (2) was originally cited from the work of Dube et al. [22], which was based on the study of solidification of AZ91 magnesium alloy (Mg- 8.3 9.7 wt.\% Al0.35 1.0 wt.\% Zn- 0.15 0.50 wt.\% Mn). The morphology as well as the arm spacing of the dendrites mainly depends on the constitutional super-cooling at the solidification front [23]. The constitutional super-cooling is decided by the equilibrium partition coefficient $\left(k_{0}\right)$ of the alloy, the content of the adding elements and the temperature gradient at the solidification front. As is known [24], the values of $k_{0}$ for AZ91 alloy and 7075 alloy are both less than unity and the two alloys both contain much high adding elements. That means, the influence factors for the solidification of the two alloys are more or less same and the relationship between cooling rate and dendrite arm spacing should be in a similar mode. Moreover, according to Dube et al. [22], Equation (2) can be used for a relatively wide cooling rate range of $10^{-1} \sim 10^{6} \mathrm{~K} \cdot \mathrm{s}^{-1}$. Thus it is quite rational using the equation to 
account for the effect of cooling rate on the dendrite arm spacing in twin-roll casting of 7075 alloy.

According to classical solidification theory [25], the solute content in the solidified phase during solidification can be calculated with the following equation:

$$
C_{S}^{*}=k_{0} C_{0}\left(1-\frac{f_{S}}{1+\alpha k_{0}}\right), \alpha=D_{S} \tau / S^{2}
$$

where $C_{S}{ }^{*}$ the solute content in the solid phase, $k_{0}$ the equilibrium partition coefficient; $C_{0}$ the original composition of the alloy; $D_{S}$ the diffusion coefficient in the solid phase, $\tau$ the partial solidification time, $S$ the half-length of dendrite spacing. From the function it is known that with the decreasing of the dendrite spacing, the solute content in the solid phase increases. Thus it can be expected that the element content inside the dendritic arms is higher in the $0.75 \mathrm{~m} / \mathrm{min}$ sheet, which can help explain the smaller $S_{e}$ in the sheet. When the element content inside the arms increased, less solute would be transferred to sheet center. Moreover, the migration channels for the elements were blocked when the dendrites were refined. As a result, the macro-segregation belt disappeared in the $0.75 \mathrm{~m} / \mathrm{min}$ sheet.

When the compound field was applied to the 7075 melt during TRC, the Lorentz force:

$$
\vec{f}=\vec{J} \times \vec{B}
$$

would be induced, where $\vec{J}$ is the current intensity and $\vec{B}$ the magnetic flux density [9]. It is a body force with its direction and amplitude changing with time. In current study, the directions of the electric current and the magnetostatic field were along the sheet length and vertical to the sheet surface, respectively. Thus the body force was along the roll width according to the left-hand rule and had a frequency of $20 \mathrm{~Hz}$ same as that of the pulsed electric field. Thus oscillation was generated in the melt when the induced body force was large enough to overcome the viscous force $[9,26]$. During the horizontal TRC, the crystal growth direction was vertical to the roll surface, opposite to that of the heat flow [8]. Thus the oscillation was vertical to the growth direction and the 
growing columnar dendrites in the mushing zone would be perturbed and broken into pieces. This can be further understood with the fact that the melt in the root area of the columnar dendrites has more solutes and thus a lower melting point [23]. Thus the dendrite root grows more slowly than the tip, which makes the root the weakest part. Meanwhile the high solute content induces changes in the local curvature of the dendrite roots, which causes them to remelt [27]. Moreover, according to Li [28], a significant difference in electronic resistivity between solid and liquid in the mushy zone drives the solid to move faster than the surrounding liquid. This results in a relative velocity and displacement between the two phases, due to which the dendrites might be segmented to some extent. As a result, the higher order dendrites lose the chance to coarsen. Moreover, the small pieces move to the solidification front and act as nucleus for new crystals and this also helps refine the microstructure. The combination of these effects results in a smaller dendrite arm spacing and the solute content inside the dendritic arms increases according to Equation (3).

According to Mahathaninwong et al. [13], the as-cast 7075 alloy mainly consists of matrix- $\alpha$ (Al) and GB eutectic phases which are mainly $\eta\left(\mathrm{MgZn}_{2}\right), \mathrm{T}\left(\mathrm{Al}_{2} \mathrm{Mg}_{3} \mathrm{Zn}_{3}\right)$ and $\mathrm{S}\left(\mathrm{Al}_{2} \mathrm{CuMg}\right)$. However, none of these intercrystalline phases are found in the as-cast TRC 7075 sheet and the content of Mg, $\mathrm{Zn}$ and $\mathrm{Cu}$ in the precipitated phases is lower. The reason for the difference might lie in the different cooling rates during casting. The interface heat-transfer coefficient during TRC is 5000 20000 W/ $\left(\mathrm{m}^{2} \mathrm{~K}\right)$ whereas the value in the secondary cooling stage in DC casting is 60 130 W/ $\left(\mathrm{m}^{2} \mathrm{~K}\right)$ [29-30]. What's more, the diameter of DC ingots is ordinarily much larger than the TRC sheet thickness. Thus the cooling rate in TRC is much higher than that in the DC casting. As a result, the dendrite arm spacing of TRC sheet is smaller. Based on Equation (3), the solute content inside the dendrite arms of TRC sheet is higher than that in the DC ingots and thus that in the GB phases decreases. The same result was also attained in Birol's work [20]. 
The different structures of the sheets after homogenization are the results of the different as-cast structures discussed above. As stated by Kim et al. [1], when the structure was refined, there would be more sites for the precipitates nucleation and the diffusion length for the elements to form the precipitates decreased. Moreover, the elements content inside the dendrite arms is enhanced in the refined structure, which results in a more uniform distribution of the elements. All these changes benefit a more homogeneous distribution of the precipitates in the homogenized sheet in Fig. 7.

According to Wang [10], the relatively high fraction of particles over $1 \mu \mathrm{m}$ in TRC sheet would result in a homogeneous recrystallized microstructure with fine grains induced by particle simulated nucleation (PSN). It can be thus speculated that the $0.75 \mathrm{~m} / \mathrm{min}$ sheet would have a more homogeneous and refined structure after hot rolling because of the more uniformly distributed phases in it. The mechanical properties of the sheet are enhanced by both the refined structure and the fine and uniformly distributed phases. Moreover, the coarse phases in Fig. 7(a) are harmful to the enhancement of sheet properties, which can also explain the inferior properties of the $1.5 \mathrm{~m} / \mathrm{min}$ sheet.

\section{Conclusions}

Two casting speeds of $1.5 \mathrm{~m} / \mathrm{min}$ and $0.75 \mathrm{~m} / \mathrm{min}$ were used in horizontal TRC of 7075 sheet to study their effects on the microstructure and properties. The effects of a compound field were also investigated.

(1) When casting speed decreases from $1.5 \mathrm{~m} / \mathrm{min}$ to $0.75 \mathrm{~m} / \mathrm{min}$, the size of the dendritic arms in the sheet decreases from $\sim 20 \mu \mathrm{m}$ to $8 \sim 13 \mu \mathrm{m}$ and the micro-segregation degree of $\mathrm{Mg}$, $\mathrm{Zn}$ and $\mathrm{Cu}$ decreases as well. The macro-segregation belt disappears in the $0.75 \mathrm{~m} / \mathrm{min}$ sheet.

(2) The microstructure of the $0.75 \mathrm{~m} / \mathrm{min}$ sheet is further refined by the compound field and the secondary dendrite arm size decreases from $8 \sim 13 \mu \mathrm{m}$ to $5 \sim 8 \mu \mathrm{m}$. The dendritic segregation in the 
field sheet is also further abated.

(3) More dot-like and needle-like segregation phases appear in the $0.75 \mathrm{~m} / \mathrm{min}$ sheet after homogenization. The $0.75 \mathrm{~m} / \mathrm{min}$ sheet shows higher tensile strength and elongation that the 1.5 $\mathrm{m} / \mathrm{min}$ sheet. The field sheet shows higher tensile strength and nearly same elongation compared with the non-field sheet.

\section{Acknowledgements}

This work was supported by the Industry-Academia-Research projects of Guangdong province,

P.R. China (Grant No. 2014B090903012, No. 2013B090200008 \& No. 2013B090600015).

\section{References}

[1] S.W. Kim, D.Y. Kim, W.G. Kim, K.D. Woo, The study on characteristics of heat treatment of the direct squeeze cast 7075 wrought Al alloy, Mater. Sci. Eng. A 304-306 (2001) 721-726.

[2] R. Arabi Jeshvaghani, H. Zohdi, H.R. Shahverdi, M. Bozorg, S.M.M. Hadavi, Influence of multi-step heat treatments in creep age forming of 7075 aluminum alloy: Optimization for springback, strength and exfoliation corrosion, Mater. Charact. 73 (2012) 8-15.

[3] R. Jayaganthan, H.-G. Brokmeier, Bernd Schwebke, S.K. Panigrahi, Microstructure and texture evolution in cryorolled Al 7075 alloy, J. Alloy. Compd. 496 (2010) 183-188.

[4] Mohan Kumar S, Pramod R, Shashi Kumar M E, Govindaraju H K, Evaluation of Fracture Toughness and Mechanical Properties of Aluminum Alloy 7075, T6 with Nickel Coating, Procedia Eng. 97 ( 2014 ) 178-185.

[5] Xin Su, Guang-Ming Xu, Ding-Hui Jiang, Distribution uniformity of added elements in twin-roll cast Al-Zn-Mg-Cu alloy by multi-electromagnetic fields, Rare Met. 34(8) (2015) $546-552$

[6] CHEN Shou-dong, CHEN Jing-chao, Simulation of microstructures in solidification of aluminum twin-roll casting, Trans. Nonferrous Met. Soc. China 22 (2012) 1452-1456.

[7] S.Y. Park, W.J. Kim, Difference in the Hot Compressive Behavior and Processing Maps between the As-cast and Homogenized Al-Zn-Mg-Cu (7075) Alloys, J. Mater. Sci. Technol. 32 (2016) 660-670. 
[8] Naiyu Sun, Burton R. Patterson, Jaakko P. Suni, Eider A. Simielli, Hasso Weiland, Lawrence F. Allard, Microstructural evolution in twin roll cast AA3105 during homogenization, Mater. Sci. Eng. A 416 (2006) 232-239.

[9] Shigeo Asai, Electromagnetic Processing of Materials---Materials Processing by Using Electric and Magnetic Functions, Springer, 2012. DOI 10.1007/978-94-007-2645-12.

[10] Lei Wang, Huashun Yu, Yun-Soo Lee, Min-Seok Kim, Hyoung-Wook Kim, Effect of microstructure on hot tensile deformation behavior of 7075 alloy sheet fabricated by twin roll casting, Mater. Sci. Eng. A 652 (2016) 221-230.

[11] X. Su, G.M. Xu, D.H. Jiang, Abatement of segregation with the electro and static magnetic field during twin-roll casting of 7075 alloy sheet, Mater. Sci. Eng. A 599 (2014) 279-285.

[12] X. Su, S.J. Wang, X. OuYang, P. Song, G.M. Xu, D.H. Jiang, Physical and mechanical properties of 7075 sheets produced by EP electro- and electromagnetic cast rolling, Mater. Sci. Eng. A 607 (2014) 10-16.

[13] N. Mahathaninwong, T. Plookphol, J. Wannasin, S. Wisutmethangoon, T6 heat treatment of rheocasting 7075 Al alloy, Mater. Sci. Eng. A 532 (2012) 91-99.

[14] Shengdan Liu, Jianghai You, Xinming Zhang, Yunlai Deng, Yubao Yuan, Influence of cooling rate after homogenization on the flow behavior of aluminum alloy 7050 under hot compression, Mater. Sci. Eng. A 527 (2010) 1200-1205.

[15] Fu-guan CONG, Gang ZHAO, Feng JIANG, Ni TIAN, Rui-feng LI, Effect of homogenization treatment on microstructure and mechanical properties of DC cast 7X50 aluminum alloy, Trans. Nonferrous Met. Soc. China 25(2015) 1027-1034.

[16] U. Hechta, L. Gránásy, T. Pusztai, B. Böttger, M. Apel, V. Witusiewicz, L. Ratke, J. De Wilde, L. Froyen, D. Camel, B. Drevet, G. Faivre, S.G. Fries, B. Legendre, S. Rex, Multiphase solidification in multicomponent alloys, Mater. Sci. Eng. R 46 (2004) 1-49.

[17] Ch. Gras, M. Meredith, J.D. Hunt, Microstructure and texture evolution after twin roll casting and subsequent cold rolling of Al-Mg-Mn aluminium alloys, J. Mater. Process. Technol. 169 
(2005) 156-163.

[18] Toshio Haga, Kenta Takahashi, Masaaki Ikawa, Hisaki Watari, A vertical-type twin roll caster for aluminum alloy strips, J. Mater. Process. Technol. 140 (2003) 610-615.

[19] Mingjun Li, Takuya Tamura, Naoki Omura, Yuichiro Murakami, Shuji Tada, Grain refinement of AZCa912 alloys solidified by an optimized electromagnetic stirring technique, J. Mater. Process. Technol. 235 (2016) 114-120.

[20] Yucel Birol, Heat treatment of twin-belt cast EN AW 7075 alloy, Mater. Charact. 63 (2012) 1-8.

[21] Amir Hadadzadeh, Mary A. Wells, Mathematical modeling of thermo-mechanical behavior of strip during twin roll casting of an AZ31 magnesium alloy, J. Magn. Alloy. 1 (2013) 101-114.

[22] R.V. Allen, D.R. East, T.J. Johnson, W.E. Borbidge, D. Liang, Magnesium Alloy Sheet Produced by Twin Roll Casting, in: J.N. Hryn (Ed.), Magnesium Technology, TMS, Indianapolis, IN, USA, 2001, 75-80.

[23] R. Abbaschian, L. Abbaschian and R.E. Reed-Hill, Physical Metallurgy Principles, 4th ed. Boston: Cengage Learning, (2009) 408-461.

[24] ASM International, ASM HANDBOOK: VOLUME 3 Alloy Phase Diagrams, 1992.

[25] W. Kurz, D.J. Fisher, Fundamentals of Solidification, fourth revised edition, 1998, Trans Tech Publications Ltd, Switzerland, 120-140.

[26] CHARLES VIVES, Effects of Forced Electromagnetic Vibrations during the Solidification of Aluminum Alloys: Part I. Solidification in the Presence of Crossed Alternating Electric Fields and Stationary Magnetic Fields, METALL. MATER. TRANS. B 27B JUNE (1996) 445-455.

[27] Fa-guo LI, Qing DONG, Jiao ZHANG, Yong-bing DAI, Ya-nan FU, Hong-lan XIE, Fu-cheng YIN, Bao-de SUN, In situ study on columnar-equiaxed transition and anaxial columnar dendrite growth of $\mathrm{Al}-15 \% \mathrm{Cu}$ alloy by synchrotron radiography, Trans. Nonferrous Met. Soc. China 24(2014) 2112-2116.

[28] Mingjun Li, Takuya Tamura, Kenji Miwa, Controlling microstructures of AZ31 magnesium 
alloys by an electromagnetic vibration technique during solidification: From experimental observation to theoretical understanding, Acta Mater. 55 (2007) 4635-4643.

[29] De Wang, Cheng Zhou, Guojin Xu, Huaiyuan A, Heat transfer behavior of top side-pouring twin-roll casting, J. Mater. Process. Technol. 214 (2014) 1275-1284.

[30] Xudong Wang, Zhaofeng Wang, Yu Liu, Fengming Du, Man Yao, Xiaobing Zhang, A particle swarm approach for optimization of secondary cooling process in slab continuous casting, Int. J. Heat Mass Transfer 93 (2016) 250-256. 